\title{
El carácter práxico de la teología: Un enfoque epistemológico
}

\author{
Francisco de Aquino ${ }^{1}$ \\ FACULTAD DE TEOLOGÍA DE FORTALEZA, BRASIL
}

\begin{abstract}
Abordaremos la problemática del carácter práxico de la teología desde un punto de vista estrictamente epistemológico. Por tanto, nos situamos en el área de la metodología teológica. Se trata, ciertamente, de un aspecto o elemento del método teológico, pero un aspecto o elemento fundamental y decisivo. Nuestro objetivo es mostrar cómo el conocimiento teológico se determina, en gran parte, por la praxis que busca inteligir. De modo que la praxis no será tratada aquí como mero objeto, asunto o tema y/o meta u objetivo de la teología, como si el quehacer teológico en cuanto tal no fuese determinado por ella. Menos aun será tratado como el conjunto de las actividades pastorales desarrolladas por la comunidad eclesial y que constituye el área de estudio da la disciplina Teología Pastoral, como si las demás áreas y disciplinas de la teología no tuviesen un carácter intrínsecamente práxico $^{2}$. La praxis será vista como momento constitutivo y determinante del conocimiento teológico en cuanto tal. En este sentido nuestra discusión quedará circunscrita rigurosamente al ámbito de la
\end{abstract}

1 Doctor en teología por la Westfälische Wilhelms-Universität de Münster (Alemania), profesor de teología en la Facultad Católica de Fortaleza y presbítero de la Diócesis de Limoeiro do Norte - CE - Brasil.

2 Son las diferentes perspectivas y abordajes de la teología práctica o pastoral (Cf. C. FLORISTAN, Teología práctica: teoría y praxis de la acción pastoral [Salamanca 2009]; M. MIDALI, Teologia pastorale o pratica. Camino storico de una riflessione fondante e cientifica [Roma 1991]; M. SzentMÁrtoni, Introdução à teologia pastoral [São Paulo 1999]; A. Brighenti, A pastoral dá o que pensar: a inteligência da prática transformadora da fé [São Paulo 2006]; A. BENTUÉ, «La pastoral como categoría teológica fundamental», Teología y Vida XXXVI [1995] 7-20; A. Vigeras, «Que cabe à Igreja fazer hoje? A concepção de teologia prática em Karl Rahner», Perspectiva Teológica 98 [2004] 99-124). 
problemática teoría-praxis. Por lo tanto, se trata de determinar los vínculos constitutivos y determinantes del proceso del conocimiento teológico (teoría) con la realidad a ser conocida por la teología (praxis).

Para eso, esbozaremos de modo más elaborado la problemática teoría-praxis (I), situaremos la discusión sobre el proceso de conocimiento teológico en el horizonte de la problemática teoría-praxis (II) y explicitaremos el carácter práxico de la teología (III). Y haremos esto dentro de la tradición teológica latinoamericana (Teología de la Liberación), sirviéndonos, sobre todo, de la intuiciones y elaboraciones de Ignacio Ellacuría.

\section{La problemática teoría-praxis}

Ciertamente, nadie niega que hay algún vínculo o nexo entre teoría y praxis. Por lo menos en la medida en que la praxis se vuelve asunto u objeto de la teoría y que la teoría puede orientar o auxiliar a la praxis. Esto es evidente. La cuestión es saber qué tipo de vínculo se da aquí y si ese es el único vínculo posible entre ambas. Vamos a ver:

Podría ser que teoría y praxis fuesen realidades completas y autosuficientes y que entre ellas no se diese más que una mera relación entre relatos que, en sí y por sí mismos, son completamente independientes uno del otro. En este caso, tendríamos dos realidades o relatos (teoría y praxis) que podrían establecer o no algún contacto entre sí (relación). Aquí se trataría de un vínculo puramente externo, en la medida en que ni la teoría sería un momento constitutivo de la praxis, ni mucho menos la praxis sería un momento constitutivo de la teoría. Esto no niega la posibilidad e incluso la necesidad del vínculo entre teoría y praxis; simplemente determina el tipo de vínculo que se da entre ellas: relación entre relatos ya constituidos.

En el fondo esta postura está enraizada y fundamentada en aquel dualismo radical que constituye y caracteriza la civilización occidental desde sus orígenes hasta nuestros días (inteligencia versus sensibilidad) ${ }^{3}$ y que origina muchos otros dualismos (sensible versus suprasensible; material versus espiritual) ${ }^{4}$. En verdad, dice Zubiri, «la filosofia clásica ha opuesto siempre el inteligir al sentir. Inclusive cuando ha intentado alguna vez con Kant unificarlos se ha tratado siempre de 'unificación', pero no de 'unidad'

3 Cf. X. ZuBIRI, Inteligencia sentiente. Inteligencia y realidad (Madrid 2006), 24.

4 Cf. I. ElLacuría, «La nueva obra de Zubiri: Inteligencia sentiente» en Escritos Filosóficos III. San Salvador: UCA, 2001, 297-317, aquí 312. 
estructural formal» ${ }^{5}$. Ese modo de encarar la sensibilidad y la inteligencia contiene una afirmación fundamental y decisiva: «Inteligir es posterior a sentir, y esa posterioridad es una oposición. Fue la tesis inicial de la filosofía desde Parménides, que ha venido gravitando imperturbablemente, con mil variantes, sobre toda la filosofia europea» ${ }^{6}$. Lo más extraño es que tal oposición se dio sin que se explicitase en qué consiste propiamente el sentir y en qué consiste propiamente el inteligir? ${ }^{7}$ Y «como no se ha determinado qué sean el inteligir y el sentir en cuanto tales, resulta que su presunta oposición queda entonces en el aire» ${ }^{8}$.

De hecho, cuando se analiza más detenidamente el sentir y el inteligir humanos, como hace Xavier Zubiri en su trilogía sobre la Inteligencia sentiente (realidad, logos y razón), se llega a otra conclusión: «El sentir humano y el inteligir no sólo no se oponen sino que constituyen en su intrínseca y formal unidad un solo y único acto de aprehensión. Ese acto en cuanto sentiente es impresión; en cuanto intelectivo es aprehensión de realidad. Por tanto, el acto único y unitario de intelección sentiente es impresión de realidad. Inteligir es un modo de sentir, y sentir es en el hombre un modo de inteligir» ${ }^{9}$. Con otras palabras, el ser humano siente inteligiendo (sentir intelectivo) ${ }^{10}$ e intelige sintiendo (intelección sentiente) $)^{11}$ Hay, por tanto, entre el inteligir y el sentir «una unidad estructural radical por la cual el sentir mismo es intelectivo e la intelección misma es sentien-

5 X. Zubiri, Ob. cit., 79.

6 Ibíd., $11 \mathrm{~s}$.

7 Cf. Ibíd., 24s, 79. «Por extraño que ello parezca, la filosofia no se ha hecho cuestión de qué sea formalmente el inteligir. Se ha limitado a estudiar los diversos actos intelectivos, pero no nos ha dicho qué sea inteligir. Y lo extraño es que esto mismo ha acontecido en la filosofia con el sentir. Se han estudiado los diversos sentires según los diversos 'sentidos' que el hombre posee. Pero se si pregunta en qué consiste la índole formal del sentir, esto es qué es el sentir en cuanto tal, nos encontramos con que en el fondo la cuestión misma no fue ni planteada» (Ibíd., 24s).

8 Ibíd., 25.

$9 \quad$ Íd. Inteligencia sentiente. Ob. cit., 13.

10 «En la impresión de realidad podemos partir de la impresión misma. Entonces 'en' esta impresión está el momento de realidad. [...] decir que el momento de realidad está 'en' la impresión es lo mismo que decir que la intelección está estructuralmente 'en' el sentir: la impresión de realidad es sentir intelectivo» (Ibíd., 82).

11 «Pero podemos describir la impresión de realidad partiendo del momento de realidad. Entonces el momento de impresión está estructuralmente 'en' el momento de realidad. [...] El sentir está así 'en' el inteligir. En su virtud, esta intelección es intelección sentiente» (Ibíd., 83). 
te» ${ }^{12}$. Así, dice Ellacuría, «desde la intelección sentiente se va a una superación radical de toda forma de dualismo entre inteligir y sentir» ${ }^{13}$. Con eso, podemos superar también la clásica separación y/o oposición entre teoría y praxis, pensando el vínculo entre ambas como algo constitutivo y no como mera relación.

En esta perspectiva, teoría y praxis no constituirían relatos completos y autosuficientes entre los cuales se pudiese o incluso se debiese establecer alguna relación, sino que serían momentos constitutivos una de la otra: la teoría sería un momento de la praxis y la praxis sería un momento de la teoría. De modo que no habría praxis sin teoría ni teoría sin praxis. De hecho, la praxis, en cuanto acción humana ${ }^{14}$, tiene como una de sus notas constitutivas la intelección. No hay praxis que no sea de alguna forma y en alguna medida inteligente: «Algún modo de teoría es inevitable en cualquier praxis humana y aun en cualquier praxis socio-histórica» ${ }^{15}$. Y la teoría, en cuanto intelección, es una nota fundamental de la acción humana que, por más irreductible que sea, solo actúa «en unidad primaria con todas las demás notas de la realidad humana» ${ }^{16}$ : Es «un momento de una

12 I. Ellacuría, Ob. cit., 336.

13 Ibíd.

14 «Como ser viviente, el hombre se halla entre cosas, externas unas, internas otras, que le mantienen en una actividad no solo constante, sino primaria; el viviente es una actividad constitutiva». Y esa actividad tiene una estructura bien determinada y constituida por tres notas o momentos fundamentales: suscitación ("lo propio de las cosas para el viviente es suscitar una acción vital"), afección ("esta suscitación modifica el estado en el sentido de alterar el tono vital que el viviente posee") y respuesta ("esta afección es una tensión hacia una respuesta adecuada, la cual deja al viviente en un nuevo estado"). Este es «el esquema de las acciones de todo ser viviente» (X. Zubiri, Sobre el Hombre [Madrid 1998], 11ss) que en la realidad humana se configura como intelección, sentimiento y volición (Cf. Ibíd., 15ss; íd. Inteligencia sentiente. Ob. cit., 282ss).

15 I. ElLacuria, «Relación teoría y praxis en la teología de la liberación» en Escritos Teológicos I. San Salvador: UCA, 2000, 235-245. aqui 235.

16 Íd. «Hacia una fundamentación del método teológico latinoamericano» en Ob. cit., 187-218, aquí 206. «La inteligencia humana tiene, sin duda, una estructura propia, por la cual se diferencia de otras notas de la realidad humana; esa estructura propia permite una precisa especialización, irreductible a lo que es propio de otras notas de la realidad humana, de modo que solo la inteligencia intelige y lo que hacen otras notas es algo formalmente distinto de este inteligir. Pero lo que hace la inteligencia, por muy formalmente irreductible que sea, lo hace en unidad primaria con todas las demás notas de la realidad humana. Por lo tanto, el reconocimiento de esta estructura propia no implica que se le atribuyan una sustantividad y una autonomía totales, pues 
praxis unitaria de la que recibe su última determinación» ${ }^{17}$. Se trata aquí, por tanto, de un vínculo interno, en el cual teoría y praxis se constituyen en respectividad ${ }^{18}$ una para con la otra (la teoría es un momento de la praxis y la praxis tiene como una de sus notas fundamentales la teoría), antes y más allá de cualquier relación.

Más que de relación (entre relatos), hay que hablar aquí, por tanto, de respectividad (de notas). Y, en este sentido, no basta afirmar que la praxis puede tornarse asunto u objeto de la teoría y que la teoría puede orientar o auxiliar la praxis, como si se tratase simplemente de relacionar relatos ya constituidos que, en principio, nada tendrían que ver uno con el otro. Es preciso reconocer que toda praxis tiene como una de sus notas fundamentales, constitutivas y determinantes la intelección y que toda teoría, en cuanto intelección, se constituye como un momento fundamental, constitutivo y determinante de una praxis, estructurada por una diversidad de notas (intelección, sentimiento y volición) coherentemente o sistemáticamente articuladas entre sí.

\section{La teología en el horizonte de la problemática teoría-praxis}

Después de esbozar la problemática teoría-praxis, situaremos la discusión sobre el proceso del conocimiento teológico en el horizonte de esa problemática, o sea, vamos a circunscribir y formular la cuestión del hacer

siempre está condicionada y determinada por la primaria unidad, que es el hombre como ser vivo» (Ibíd., 206s).

17 Íd. «Relación teoría y praxis en la teología de la liberación». Op. cit.

18 Para Zubiri, «respectividad es un carácter metafísico de la realidad, y no simplemente una relación o propiedad, entre otras, de las cosas reales». (X. ZubIrI, «Respectividad de lo real» en íd. Escritos menores: 1953-1983 [Madrid 2006], 173-215, aquí 173). Esta se refiere tanto a la «constitución misma de la cosa real en cuanto real», como a su «actualidad» mundanal, como, aun, a su «mera actualidad intelectiva». En otras palabras, esta se refiere a «la estructura transcendental de la apertura de lo real como 'realidad mundanal suya', de lo real como 'realidad actual' en el mundo, y de lo real mundanal como 'meramente actual' en la intelección. Realidad suya, ser, intelección, son tres momentos estructurales de la respectividad de lo real». En cuanto «aspectos de la apertura de la formalidad de realidad», cada uno fundamenta al siguiente. «Precisamente por esto, ni realidad suya, ni ser ni intelección son relación; son, en última instancia, respectividad metafísica» (Ibíd., 215). La distinción zubiriana entre «relación»e «respectividad» es algo fundamental en la filosofía e en la teología de Ellacuría. Ella permite superar muchas formas de dualismo y aprehender la realidad, simultáneamente, en su riqueza irreductible de elementos, aspectos y dimensiones y en su unidad radical. 
teológico en términos de la problemática teoría-praxis. Eso no significa que el hacer teológico haya sido siempre comprendido y formulado en estos términos, aunque no se puede negar que la teología siempre mantuvo conscientemente algún vínculo y/o interés práxico, por lo menos en cuanto actividad eclesial y en cuanto servicio a la fe, por no hablar de los intereses sociales y políticos más o menos explícitos. Evidentemente, se puede discutir si ese vínculo fue suficientemente explicitado, elaborado de modo satisfactorio y desarrollado y asumido de modo consecuente. Este es otro asunto. En todo caso, no se puede negar sin más el carácter y el interés práxicos de la teología a lo largo de la historia. De modo que no nos preguntaremos aquí si la teología tuvo/tiene o no vínculos e intereses práxicos. Esto es evidente. Lo que nos interesa es ver cómo ella va comprendiendo, elaborando y desarrollando ese vínculo.

Naturalmente, esto no siempre ha sido encarado y desarrollado por la teología. Al contrario. Son poquísimos los teólogos que se han confrontado explícitamente con esta cuestión. Normalmente se hace teología. De vez en cuando, se problematiza el hacer teológico. De cualquier manera, confrontándose o no con esa cuestión, el hacer teológico implica siempre una determinada concepción del saber (respecto a la praxis), más o menos consciente y/o elaborada. De modo que la problemática del vínculo de la teología con la praxis está siempre presente, sea o no explicitada y tematizada. Y es esto lo que nos permite situar el hacer teológico en el horizonte de la problemática teoría-praxis.

Claro que no podemos ni pretendemos aquí mostrar cómo se ha dado este vínculo en las más diversas teologías desarrolladas a lo largo de los siglos. Ni siquiera pretendemos mostrar cómo se da ese vínculo en las teologías actuales. En todo caso, no obstante el peligro de simplificación y reduccionismo, podemos identificar en la historia de la teología cristiana tres períodos en los que han predominado determinadas concepciones del hacer teológico en lo que se refiere al vínculo de la teología con la praxis. Es lo que intentaremos esbozar a continuación.

El primer período corresponde a la teología bíblica, desarrollada en el horizonte cultural semítico, aunque en diálogo con el horizonte cultural helenista y asimilando algunos de sus elementos o aspectos. Claro que en la Biblia no se encuentra ninguna teoría del conocimiento ni siquiera una definición rigurosa del mismo. Esta no es un libro de epistemología y, por tanto, no pretende mostrar cómo se da el proceso del conocimiento ni de- 
finir el conocimiento en cuanto tal. Pero también es claro que la Biblia habla mucho de conocimiento y que al hablar de él lo concibe de un modo muy concreto ${ }^{19}$. Tal concepción no aparece en forma de una definición abstracta del conocimiento (la Biblia no define el conocimiento en cuanto tal), sino en la descripción de procesos concretos de conocimiento (describe el conocimiento de determinadas realidades). Y ahí el conocimiento aparece siempre como algo fundamentalmente experiencial, práxico. Conocer a Dios, por ejemplo, es vivir en comunión con él, realizar su voluntad. En palabras del profeta Jeremías: «Juzgaba la causa del desamparado y del pobre. Yavé te pregunta: ‘Conocerme no es actuar en esa forma?’》 (Jr 22, 16). En palabras de San Juan: «Vean cómo sabremos que lo conocemos: si cumplimos sus mandatos. Si alguien dice: «Yo lo conozco», pero no guarda sus mandatos, ése es un mentiroso y la verdad no está en él. En cambio, si uno guarda su palabra, el auténtico amor de Dios está en él. Y vean cómo conoceremos que estamos en él: si alguien dice: «Yo permanezco en él», debe portarse como él se portó» (1Jn 2, 3-6); «El que no ama no ha conocido a Dios, pues Dios es amor» $(1 \mathrm{Jn} 4,8)$. No se trata tanto de especulación abstracta y de conceptos formales, sino de experiencia, de praxis. Solo en la experiencia, en la praxis se da conocimiento real y verdadero. Como dice Clodovis Boff, «el conocer bíblico es propiamente un conocer concreto. Tiene un contenido activo que incluye una dimensión afectiva y volitiva. Podríamos trazar la ecuación: Conocer $=$ Amar $=$ Hacer. Así, conocer a Dios es, por un lado, amarlo, adorarlo, confiar en él; por otro, es observar la Torá, es practicar la solidaridad y la justicia». Con otras palabras, «el conocer bíblico se da por dos caminos: el del phatos: por el sentir, experimentar; el de la praxis; por el hacer, practicar. Tal es la síntesis de la gnoseología bíblica» ${ }^{20}$. En esta perspectiva, como bien advierte

19 Cf. H. Zimmermann, «Conhecimento» en J. Bauer, Dicionário de teologia bíblica. VI (São Paulo 1988), 204-210; G. Ziener, «Palavra» en Ibíd., 794-798; J. CorbAN - A. VAnhoye, «Conhecen» en X. León-Dufour, Vocabulário de teologia bíblica (Petrópolis 1972), 165-169; C. Boff, Teoria do método teológico, (Petrópolis 1998), 188-192.

20 C. Boff, Ob. cit., 188. Lo raro es que, después de describir tan bien el modo bíblico de conocer frente al modo griego de conocer, al intentar articular ambos modos de conocimiento, evitando una contraposición pura y simple entre ellos, Boff acaba negando el modo bíblico de conocer en función del modo griego de conocer: «Ora, a teologia não é justamente o esforço de conjugar as duas [concepções], no sentido de articular a sabedoria bíblica e a ciência grega? Não é a tentativa de dar ao conteúdo da Sabedoria (bíblica) a forma da Ciência (grega)? Enfim, não é com a Bíblia que se aprende a fazer teologia, mas com Grécia. E vice-versa: não é com Grécia que se aprende teologia como conteúdo, mas sim com a Bíblia. E ei-las, pois, corretamente harmoni- 
Antonio González, «conviene no olvidar que el término hebreo habitualmente traducido por 'palabra' y que está en el trasfondo del lógos joánico no es otro que dabar, el cual tanto puede significar 'palabra' como 'hecho', 'suceso', 'acontecimiento' e incluso también 'cosa'. Por eso, las traducciones indoeuropeas (tanto el logos conceptual helénico, como el verbum psicolinguístico de Agustín o el Wort luterano) son enormemente unilaterales y se mueven [...] dentro del fenómeno [...] denunciado por Nietzsche de la escisión entre inteligencia y sentir en el pensamiento occidental desde Parménides, en virtud del cual palabra e acción aparecen como dos ámbitos no solo diferentes, sino también distintos y hasta contrapuestos $\rangle^{21}$. Pero esta no es la perspectiva bíblica del conocimiento. Al contrario. En la Biblia, inteligencia y sentido, conocimiento y acción no solo no se oponen, sino que se implican y se determinan mutuamente. El conocimiento bíblico tiene un carácter fundamentalmente práxico-experiencial.

El segundo período corresponde a la elaboración y desarrollo de la teología cristiana en el horizonte cultural greco-helenista. Casi toda la teología cristiana fue elaborada en este horizonte cultural. De hecho, la «filosofia helénica, platónica y aristotélica fue durante siglos el marco teórico elegido para interpretar toda la realidad, también la realidad de las relaciones de Dios con el hombre y del hombre con Dios» ${ }^{22}$. Y este horizonte teórico, como afirma Xavier Zubiri, está marcado por un dualismo entre inteligencia y sensibilidad con decisivas consecuencias para la concepción del hacer teológico y para su realización. No es que el horizonte bíblico haya sido pura y simplemente substituido por el horizonte griego sin que haya influido en él o lo haya alterado en alguna medida. Los procesos de inculturación son más complejos de lo que parece. En todo caso, dice Ellacuría a propósito del carácter histórico de la salvación, «en el tránsito de lo que era fundamentalmente una experiencia biográfica e histórica, con su propia interpretación teórica, a una formulación metafísica había quedado diluida la historicidad, en beneficio de una esencialidad estática», una vez que «el paradigma de interpretación racional era la explicación de la naturaleza con sus propias categorías metafísicas. Respecto de la natura-

zadas» (Ibíd., 192). Pero si la Biblia no ofreciese más que el contenido de la teología y si el único modo posible de conocer fuese el modo griego, no habría por qué hablar de modo bíblico de conocer.

21 A. GonzÁLEz, Trinidady liberación. La teología trinitaria considerada desde la perspectiva de la teología de la liberación (San Salvador 1994), 60.

22 I. Ellacuria, «Historia de la salvación» en ob. cit., 597-628, aquí 597. 
leza, la historia carecía de realidad y de razonabilidad (científica)»» ${ }^{23}$ Y aquí vemos cómo el vínculo entre el dualismo inteligencia $\mathrm{X}$ sensibilidad y el dualismo teoría $\mathrm{X}$ praxis es mucho más estrecho de lo que parece: el primero conduce al segundo y lo fundamenta; el segundo supone el primero y lo profundiza. Por eso la teología desarrollada en este horizonte teórico es marcadamente una teología dualista (cuerpo X alma; materia X espíritu; mundo X Dios; etc.) y la concepción del hacer teológico que subyace a ella, explicitada o no, se caracteriza por un dualismo epistemológico más o menos radical (inteligencia X sensibilidad; teoría X praxis). Por eso Tomás de Aquino, aun admitiendo que en la Sagrada Doctrina haya cuestiones o dimensiones especulativas y prácticas, acaba defendiendo que esta es «más especulativa que práctica» (STh I, q.1, a.4). Incluso un Karl Rahner, con toda la influencia de la tradición ignaciana y con toda su abertura al mundo moderno y a las ciencias contemporáneas, no consiguió librarse totalmente del dualismo sensibilidad X inteligencia. Habla, ciertamente, de «espíritu en el mundo» (Geist in Welt), pero no llega a tematizar el carácter mundano del espíritu (weltlicher Geist). Es que, en el fondo, dentro de la tradición filosófica occidental, continúa comprendiendo la intelección como abstracción, juicio, conceptualización ${ }^{24}$. Por más que los sentidos puedan ofrecer a la inteligencia el material a ser inteligido, el inteligir en sí mismo no es sentiente, sino concepiente, para usar la formulación de Zubiri ${ }^{25}$. Probablemente por eso, Rahner tampoco consiguió superar totalmente el

23 Ibíd., 597s. «Sólo podía haber ciencia de lo universal. Lo no permanente y unívocamente repetible caía fuera del ámbito del saber y quedaba reducido a mera opinión. Los avatares de las biografías personales y los sucesos de La historia de los pueblos podían convertirse en ejemplos y en impulso, pero no era base suficiente para alcanzar un sólido saber sobre el que fundamentar el conocimiento del mundo y la conducta del hombre [...]. La historia y lo histórico más habían hecho por oscurecer la límpida y refulgente seguridad de la razón, apoyada en la naturaleza, que por ayudar a describir lo que es la esencia de la naturaleza humana» (Ibíd., 598).

24 Cf. K. RAHner, Hörer des Wortes. Zur Grundlegung einer Religionsphilosophie (München 1971), 63-77; M. A. de Oliveira, «'É necessário filosofar na teologia’: unidade e diferença entre filosofia e teologia em Karl Rahner» en P. Oliveira - C. PAul, Karl Rahner em Perspectiva (São Paulo 2004), 201-218, especialmente 214s.

Cf. X. Zubiri, Inteligencia sentiente. Ob. cit., 83ss. «La filosofía clásica [...] piensa que hay dos actos: el acto de sentir da 'a' la inteligencia lo que esta va 'a' inteligir [...] Decir que los sentidos dan 'a' la inteligencia lo que esta va a inteligir es suponer que la inteligencia tiene como objeto primario y adecuado lo que los sentidos presentan 'a' ella. En su virtud, la inteligencia sería entonces lo que llamo inteligencia sensible. Inteligencia sensible es inteligencia 'de' lo sensible» (Ibíd., 83) e ella consiste en concebir lo sensible. De ahí su carácter «concipiente» (Ibíd., 86s). 
dualismo teológico reinante. Aunque haya superado el dualismo clásico naturaleza X gracia a través del concepto existencial sobrenatural (übernatürliches Existential) y haya reducido el concepto naturaleza a un concepto residual (Restbegriff) $^{26}$, continúa hablando de dos historias (profana y sagrada). Aunque se trate de historias coextensivas ${ }^{27}$ (koextensiv), se trata de dos historias ${ }^{28}$. De modo que la teología occidental está marcada por un dualismo más o menos radical entre inteligencia y sensibilidad y, consecuentemente, entre teoría y praxis.

El tercer período corresponde a la renovación teológica que se desarrolla en Europa después de la Segunda Guerra Mundial y se consolida en la Iglesia católica en el movimiento de renovación conciliar, particularmente en su recepción y desarrollo en América Latina con la teología de la Liberación $(\mathrm{TdL})^{29}$. Sea por la necesidad y urgencia de transformaciones sociales, políticas, económicas, culturales y religiosas (Europa posguerra, movimientos de liberación en América Latina, Vaticano II, Medellín etc.), sea por el descubrimiento del carácter histórico del conocimiento (filosofías hermenéuticas, filosofías del lenguaje, filosofías de la vida, de la acción, de la praxis, ciencias sociales, históricas, culturales, etc.), la teología fue poco a poco explicitando y enfatizando su origen y su finalidad práxica aunque no siempre haya conseguido percibir y formular adecua-

26 Cf. K. RAhner, «Über das Verhältnis von Natur und Gnade» en íd., Schriften zur Theologie I (Einsiedeln-Zürich-Köln 1954), 323-345.

27 Cf. íd., Curso Fundamental da fé (São Paulo 1989), 176.

28 Vale la pena ver la crítica lúcida y consecuente de Antonio González a Rahner (Cf. A. GONZÁLEZ, «El problema de la historia en la teología de Gustavo Gutiérrez», Revista Latinoamericana de Teología 18 [1989] 335-364, aquí 341-349; íd. Teología de la praxis evangélica. Ensayo de una teología fundamental [Santander 1999], 32-43).

29 En 1975 constataba Juan Alfaro en un encuentro sobre el método de la teología latinoamericana en México: «Durante los últimos treinta años la teología católica está viviendo un proceso de cambios profundos. Se trata realmente de un fenómeno nuevo en su historia, que desde el siglo XIII se había mantenido (salvo raras excepciones) en una sorprendente homogeneidad de problemas y de método [...] A partir de la Segunda Guerra Mundial se inició un movimiento acelerado de evolución que se hace visible ante todo en la renovación de la temática teológica [historia, realidades terrenas, mundo, progreso humano, esperanza, liberación, política, praxis]. Toda esa temática nueva lleva una orientación común: el interés por la dimensión histórica, comunitaria, intra-mundana de la existencia cristiana» (J. Alfaro, «Problemática actual del método teológico en Europa» en E. Ruiz Maldonaldo, Liberación y cautiverio. Debates en torno al método de la teología en América Latina [México 1976], 409-429, aquí 409). 
damente el carácter práxico del conocimiento en cuanto tal; primero en Europa (Moltmann, Metz, Schillebeeckx) ${ }^{30}$, después en América Latina con la teología de la liberación ${ }^{31}$. Aquí, especialmente se ha insistido en el vínculo teoría-praxis. Aunque con concepciones distintas de la praxis (vida cristiana, cultura popular, actividad social y política, reinado de Dios, etc.) y de su vínculo con la teoría (acto primero - acto segundo, mediaciones, círculo hermenéutico, momento de la praxis), los teólogos de la liberación siempre entendieron la TdL como una teología de la praxis: «un momento del proceso por medio del cual el mundo es transformado» (Gustavo Gutiérrez) ${ }^{32}$; una especie de praxeología de la liberación (Hugo Hassmann) ${ }^{33}$; momento consciente y reflejo de la praxis eclesial (Ignacio Ellacuría $)^{34}$; «teología de lo político y sus mediaciones» (Clodovis Boff) ${ }^{35}$; intellectus amoris (Jon Sobrino) ${ }^{36}$, entre otros. El problema es que esto siempre fue mucho más presupuesto que explicitado y elaborado, Como si fuese algo evidente e indiscutible y como si todos pensasen y dijesen lo mismo al hablar de teoría-praxis. Con rarísimas excepciones los teólogos de la liberación casi nunca se confrontaron de manera más profunda y consecuente con esa problemática. Y los pocos que lo hicieron, Clodovis Boff e Ignacio Ellacuría, partieron de presupuestos teóricos tan diferentes que llegaron a conclusiones no solo distintas, sino, en ciertos aspectos, incluso contrarias.

Clodovis Boff, apoyado en una concepción idealista del saber e del conocimiento, (Aristóteles, Tomás de Aquino, Althusser) ${ }^{37}$, llega a afir-

30 Cf. Ibíd., 421-429.

31 Cf. A. GonzÁLez, «La vigencia del 'método teológico' de la teología de la liberación», Sal Terrae 983 (1995) 667-675.

32 G. GutiÉRrez, Teologia da libertação: perspectivas (São Paulo 2000), 74.

33 Cf. H. Assmann, Teología desde la praxis de la liberación. Ensayo teológico desde la América dependiente (Salamanca 1973), 62-65.

34 Cf. I. ElLacuría, «La teología como momento ideológico de la praxis eclesial» en ob. cit., 163-185.

35 Cf. C. Boff, Teologia e prática: teologia do político e suas mediações (Petrópolis 1993).

36 Cf. J. Sobrino, El principio-misericordia: bajar de la cruz a los pueblos crucificados (Santander 1992), 47-80.

37 C. Boff, Ob. cit., 22, 29ss; íd. «Como vejo a teologia latinoamericana trinta anos depois» en susin, L. C. [Org], O mar se abriu: Trinta anos de teologia na América Latina (São Paulo 2000), 79-95, aquí 86. «La intelección se fue subsumiendo progresivamente en ser declaración de lo que la cosa es, es decir, se fue identificando intelección y logos predicativo. Fue el gran descubrimiento de Platón en el Sophistes, que culminó en 
mar que «las cosas reales permanecen atrás del proceso cognitivo» ${ }^{38}$, que «la praxis no es ninguna mediación teórica»" y que «una práctica teológica como tal solo es 'culpable' de los criterios de su gramática, o sea, del conjunto de las reglas que organizan su discurso» ${ }^{40}$. Es como si el conocimiento fuese autosuficiente, completamente independiente de la realidad, reducido a su momento discursivo y como si la verdad se redujese a la coherencia interna y al rigor de la argumentación, independientemente de si ese sistema discursivo, por más coherente y lógico que sea, expresa/traduce o no la realidad tal como ella es y se da a conocer. En esta perspectiva, claro, la praxis no es un momento constitutivo del proceso de conocimiento teológico en cuanto tal. En la formulación de Boff, esta puede ser materia prima de la teología y/o medio en el cual el teólogo vive (medium in quo), pero jamás medio con el cual se hace teología (medium quo ${ }^{41}$. Consecuentemente, el punto de partida y el principio fundamental de la teología solo puede ser para Boff la positividad de la fe $(\text { fides quae })^{42}$, aunque reconozca que en su hacer teológico la teología oriental ha privilegiado la dimensión experiencial de la fe (fides qua) y la TdL ha privilegiado la dimensión práxica de la fe ${ }^{43}$. Boff asume, por tanto, una concepción del saber y del conocimiento, en la que la praxis no interfiere directamente en la teoría teológica: está antes (presupuesta) o después (como objetivo) ${ }^{44}$ Y así, además de reducir el conocimiento teológico a su momento discursivo y de no asumir consecuentemente la

Aristóteles, para quien el logos mismo es apóphansis de lo que la cosa es. Es lo que llamo logificación de la inteligencia» (X. ZuBIRI, Ob. cit., 86). «Por este mismo camino se fue desviando la filosofía escolástica, tan apreciadora de Aristóteles en sus diferencias con Platón que no se dio cuenta de las gravísimas consecuencias que, para un verdadero realismo, implicaba la teoría aristotélica de la inteligencia» (I. ElLAcuría, «La superación del reduccionismo idealista en Zubiri» en Escritos Filosóficos III (San Salvador 2001), 403-430, aquí 405).

C. Boff, Teologia e prática: teologia do político e suas mediações, Ob. cit., 147. Íd. «Teologia e prática», REB 36/144 (1976) 789-810, aquí 796.

Íd. Teologia e prática: teologia do político e suas mediações, Ob. cit., 60.

Cf. Ibíd., 157, 377, 385.

Íd., Teoria do método teológico, Ob. cit., 111; íd., «Retorno à arché da teologia» en L. C. Susin (org). Sarça ardente. Teologia na América Latina: prospectiva (São Paulo 2000), $145-$ 187, aquí 148 s.

43 Cf. íd., «Teología» en J. Tamayo-Acosta, Nuevo diccionario de teología (Madrid 2005), 866-870, aquí 866s.

44 Íd. Teologia e prática: teologia do político e suas mediações, Ob. cit., 147. 
dimensión práxica de todo lenguaje (también teológico), acaba negando la densidad epistemológica de la praxis que, al menos teóricamente, llega a admitir en algún momento ${ }^{45}$. De esta manera, niega, de hecho, una de las intuiciones y uno de los principios teóricos más fecundos y más determinantes de esa nueva manera de hacer teología que es la TdL: el primado de la praxis. $\mathrm{Y}$ al negar el carácter práxico del conocimiento, acaba negando la otra intuición fundamental y determinante de la TdL en cuanto teoría: la perspectiva del pobre y oprimido como lugar teológico fundamental, como si el conocimiento fuese neutro y estuviese por encima de los conflictos sociales.

Ignacio Ellacuría, a su vez, apoyado en una concepción praxico-realista del saber y del conocimiento (Xavier Zubiri) ${ }^{46}$, (1) comprende la intelección humana como aprehensión de la realidad y enfrentamiento con ella ${ }^{47}$, (2) afirma que «la principal fuente de luz [de la teoría] es, ciertamente, la realidad y no quien sabe qué aprióricas condiciones del sujeto humano», aunque dejando claro que «esa realidad es sólo fuente de luz referida a la inteligencia; a una inteligencia, claro está, que a su vez esté vertida a la realidad $»^{48}$, (3) habla de la teoría como un momento de la praxis: momento teórico de la praxis ${ }^{49} \mathrm{y}$, consecuentemente, trata la teoría teológica como un momento de la praxis teologal ${ }^{50}$. Evidentemente, se trata de un momento irreductible con estructura y dinamismo propios, como exigencias, actividades y aparato técnico específicos, pero de un momento de un proceso más amplio que es la praxis teologal -la realización histórica del reinado de Dios. En esta perspectiva, la praxis teologal no queda simplemente atrás (presupuesta) o delante (como objetivo) de la teoría teológica, como para Boff, sino que es parte del proprio proceso de construcción de la teoría

45 Íd. «Prefácio auto-crítico» en Ibíd., III-XII, aquí V.

46 Cf. I. Ellacuría, «Hacia una fundamentación del método teológico latinoamericano» en ob. cit., 187-218, aquí 206, Nota 32.

47 Cf. Ibíd., 207.

48 Íd., «Función liberadora de la filosofía» en Escritos Políticos I (San Salvador 1993), 93121, aquí 105. «La realidad hace su trabajo, pero la inteligencia hace también el suyo y la respectividad entre ambas cobra distintas modalidades que, sin negar o anular la prioridad de la realidad, no por eso anula el dinamismo y aun la actividad propias de la mente humana en el afán de arrancar toda su luz a la realidad mediante distintos enfoques, que la propia inteligencia va generando» (Ibíd.).

49 Ibíd., 111.

50 Cf. íd. «Relación teoría y praxis en la teología de la liberación». Ob. cit., 235; íd. «La teología como momento ideológico de la praxis eclesial». Ob. cit., 171. 
teológica (medium quo). Sea en la medida en que constituye la realidad a ser teologizada y, así, determina, de alguna manera, su acceso intelectivo; sea en la medida en que produce y/o media las propias posibilidades intelectivas (estructura del pensamiento, conceptos etc.); sea en la medida en que direcciona el hacer teológico en función de determinados intereses más o menos legítimos desde el punto de vista evangélico; sea en la medida en que se constituye en lugar de historización y de verificación de la teoría teológica. Ellacuría parte, por tanto, de una concepción del saber y del conocimiento que le permite superar la tradicional y dominante visión idealista del conocimiento teológico, de la cual Boff es un ejemplo eximio, y asumir de modo consecuente, teórica y teológicamente, la densidad epistemológica de la praxis y, con ella, el carácter determinante del lugar social de los pobres y oprimidos en el hacer teológico.

Es en esta perspectiva abierta por Ignacio Ellacuría como queremos abordar ahora el carácter práxico de la teología. Intentaremos mostrar cómo la praxis teologal es determinante y constitutiva de la teoría teológica, o sea, cómo el proceso de conocimiento teológico es un proceso constitutivamente práxico.

\section{El carácter práxico de la teología}

Habiendo formulado adecuadamente la problemática teoría-praxis y habiendo situado la teología en el horizonte de esa problemática, falta ahora explicitar el carácter práxico de la teología. Esto tiene que ver con la realidad a ser inteligida por la teología (1), con el desarrollo de la actividad intelectiva (2), con el carácter interesado de esa actividad (3) y con el proceso de verificación y de historización de la teología (4). Veamos.

\section{Realidad a ser inteligida por la teología}

El carácter práxico de la teología se refiere antes de todo a la propia realidad a ser inteligida por ella. Diferente de lo que se suele pensar y de lo que da a entender una mirada meramente etimológica de la palabra (Theos = Dios y logia $=$ palabra), la teología no trata de Dios sin más. Trata de Dios, sí, en cuanto y en la medida en que se hace presente y actúa en la historia. Trata, por tanto, de la acción de Dios en la historia que es siempre, de alguna forma y en alguna medida, re-acción ante determinadas situaciones y acontecimientos (salvación) e inter-acción con personas e pueblos concretos (Pueblo de Dios - Iglesia). De ahí la insistencia de Ellacuría en que el 
asunto u objeto de la teología cristiana no sea Dios sin más, sino el reinado de Dios $^{51}$.

«Evidentemente no se trata de la materialidad del término» ${ }^{52}$, como si no fuese posible formular el asunto de la teología cristiana de otro modo. Pero tampoco se trata aquí de una mera «fórmula verbal o de un rodeo estilístico para hablar sin más de Dios» ${ }^{53}$, como si no hubiese razones objetivas para preferir esta expresión a otras. La opción de Ellacuría por la expresión reinado de Dios se da tanto por su carácter práxico (acción de Dios en la historia) ${ }^{54}$, cuanto por su referencia directa a Jesucristo (centro de su vida y misión) ${ }^{55}$ y a su Iglesia (Pueblo de Dios - Iglesia) ${ }^{56}$, cuanto por su carácter salvífico (parcialidad por lo pobres y oprimidos) ${ }^{57}$, cuanto, aún, por tu potencial englobante y totalizador del asunto de la teología cristiana (Dios y su reinado en la historia) ${ }^{58}$.

Pero con esto aún no lo hemos dicho todo. El carácter práxico de la teología, en cuanto teoría, no se deduce simplemente de la afirmación

51 Cf. íd., «Fe y justicia» en Escritos Teológicos III (San Salvador 2002), 307-373, aquí 311; íd. «La teología como momento ideológico de la praxis eclesial». Ob. cit., 175s; íd., «Relación teoría y praxis en la teología de la liberación», Ob. cit., 235, 240s; íd., «Teología de la liberación frente al cambio socio-histórico en América Latina» en Escritos Teológicos I, Ob. cit., 313-345, aquí 315; íd., «Aporte de la teología de la liberación a las religiones abrahámicas en la superación del individualismo y del positivismo»en Escritos Teológicos II (San Salvador 2000), 193-232, aquí 202s.

52 Íd., «Recuperar el reino de Dios: Desmundanización e historización de la Iglesia» en ob. cit., 307-316, aquí 312.

53 Íd., «La teología como momento ideológico de la praxis eclesial», ob. cit., 176.

54 Cf. íd., «Recuperar el reino de Dios: Desmundanización e historización de la Iglesia» en ob. cit., 314s; íd., «La teología como momento ideológico de la praxis eclesial», ob. cit., 167s, 178ss; íd., «Hacia una fundamentación del método teológico latinoamericano» en ob. cit., $212 \mathrm{~s}$.

55 Cf. íd., «Recuperar el reino de Dios: Desmundanización e historización de la Iglesia» en ob. cit., 313s; íd., «La teología como momento ideológico de la praxis eclesial», ob. cit., 175s; íd., «Aporte de la teología de la liberación a las religiones abrahámicas en la superación del individualismo y del positivismo», ob. cit., aquí 202 s.

56 Cf. íd., «Iglesia como pueblo de Dios» en Escritos Teológicos II, ob. cit., 317-342.

57 Cf. íd., «Recuperar el reino de Dios: Desmundanización e historización de la Iglesia» en Ob. cit., 315s; íd., «La teología como momento ideológico de la praxis eclesial», Ob. cit., 182ss.

58 Cf. íd., «La teología como momento ideológico de la praxis eclesial», ob. cit., 176ss; íd., «Teología de la liberación frente al cambio socio-histórico en América Latina», ob. cit., 315s. 
de que ella trata del reinado de Dios o de la acción salvífica de Dios en la historia, por tanto de una praxis. Esta tiene que ver sobre todo con el carácter determinante de la realidad a ser inteligida en el propio proceso de intelección. Es que el modo de intelección depende en gran parte de la realidad a ser inteligida: la intelección de una realidad puramente biológica es distinta de la intelección de una realidad personal; la intelección de una realidad puramente espiritual (si es que es posible) es distinta de la intelección de una realidad histórica, por más espiritual que sea. Siendo así, la determinación del reinado de Dios como asunto de la teología es, en gran medida, la determinación de su propio proceso de intelección, una vez que el acceso intelectivo a una realidad cualquiera depende en gran parte del modo como esta realidad está constituida y se deja inteligir.

El carácter práxico de la teología tiene que ver, por tanto, con la realidad a ser intelegida (reinado de Dios como praxis) y con la determinación del propio proceso de intelección por la realidad a ser inteligida (reinado de Dios como determinante de su acceso intelectivo). Tanto por el asunto como por el modo de tratarlo, la teología es una actividad fundamentalmente práxica.

\section{Desarrollo de la actividad intelectiva}

Pero el carácter práxico de la teología no tiene que ver solo con el reinado de Dios en cuanto asunto de la teología y en cuanto determinante de su acceso intelectivo. Tiene que ver también con el propio quehacer teológico, en cuanto actividad intelectiva. Pues la actividad intelectiva es una actividad intrínsecamente práxica.

Primero, por ser ella misma «uno de los momentos esenciales de toda posible praxis ${ }^{59}$ : la teología es un momento de la praxis del reinado de Dios. Como vimos anteriormente, por más irreductible que sea y por más importante y determinante que sea, la actividad intelectiva es solamente una nota de la acción humana y solo se da en respectividad e interacción con las otras notas de la acción humana. En sentido estricto ni siquiera deberíamos hablar de actividad intelectiva, como si fuese una actividad completa frente a actividades no intelectivas. Deberíamos hablar siempre de una nota o de un momento de la acción humana. Sin contar que, dependiendo de la realidad a ser inteligida, como es el caso del reinado de

59 Íd. «Hacia una fundamentación del método teológico latinoamericano» en Ob. cit., 211. 
Dios, el conocimiento, además de ser un momento de la praxis, necesita de la praxis «no sólo para su comprobación científica, sino también para ponerse en contacto con la fuente de muchos de sus contenidos» ${ }^{60}$.

Segundo, por el carácter intrínsecamente práxico del momento intelectivo de la acción humana. Su desarrollo depende, en gran parte, de las posibilidades intelectivas disponibles en un determinado momento, de su apropiación y, a partir de ella, de la creación de nuevas posibilidades intelectivas. Por un lado, depende en cada momento de las posibilidades teóricas disponibles. Estas «se constituyen como resultado de una marcha histórica y representan el substrato desde el cual se piensa» ${ }^{61}$. Y esto es distinto en cada época, en cada pueblo, en cada situación. No se cuenta siempre con las mismas posibilidades teóricas ${ }^{62}$. Pero siempre se cuenta con algunas posibilidades y solamente a partir de ellas y con ellas se da el proceso de intelección. Ellas lo condicionan positiva (posibilitándolo) o negativamente (dificultando o impidiéndolo). Por otro lado, «la inteligencia, incluso en los casos más teóricos, tiene un momento de opción ${ }^{63}$. Y aquí reside el carácter fundamentalmente práxico del momento intelectivo de la acción humana. Es preciso optar entre las posibilidades disponibles en cada momento intelectivo y, a partir de ellas, ir creando nuevas posibilidades intelectivas. El proceso de apropiación de posibilidades intelectivas se va constituyendo, así, como un proceso de capacitación intelectiva: «La constitución de la posibilidad real es ella misma procesual y es lo que formalmente ha de entenderse como capacitación; la capacitación es un proceso por el que se va incorporando al sujeto en cuestión un poder-poder, un poder posibilitar, un poder hacer posible» ${ }^{64}$. De modo que ninguna

60 Ibíd.

61 Ibíd., 209.

62 «No era posible, por ejemplo, fundamentar la teoría de la relatividad si no desde unas determinadas posibilitaciones teóricas, proporcionadas por la historia real de la matemática y de la física. De la misma forma, no son realmente posibles determinadas lecturas de la fe si no es desde determinaciones históricas muy precisas, que hacen posible, realmente posible, situaciones concretas y mediaciones históricas diversas» (Ibíd.).

63 Ibíd., 209.

64 Íd., Filosofia de la realidad histórica (San Salvador 1999), 554. «El concepto de capacidad busca expresar esta constitución del poder en cuanto logra hacer un poder. [...] con ella asistimos no a algo que atañe simplemente al ejercicio de unas potencias, sino a lo que abre un ámbito u otro de posibilidades: más que a la actualización de una u otra posibilidad, en el caso de las capacidades nos encontramos con la constitución del ámbito mismo de un tipo de posibilidades o de otro. En este sentido, no solo se 
formulación teórica, por más abstracta y especulativa que sea, se explica, simplemente, a partir de sí misma. Depende siempre, en alguna medida, de las posibilidades intelectivas disponibles y apropiadas y de la capacitación para la creación de nuevas posibilidades intelectivas.

Sea en cuanto momento constitutivo de la praxis, sea en cuanto proceso de apropiación y creación de posibilidades intelectivas, el desarrollo de la actividad intelectiva se constituye, por tanto, como un proceso fundamentalmente práxico. Además de ser un momento de la praxis, es un momento práxico.

\section{Carácter interesado de la actividad intelectiva}

Además de la realidad a ser inteligida, (reinado de Dios como asunto de la teología y como determinante de su acceso intelectivo) y del propio proceso de intelección (momento de la praxis y momento práxico), el carácter práxico de la teología tiene que ver también con los intereses inherentes a toda actividad intelectiva.

En cuanto momento de la praxis (intelección-sentimiento-volición) y en cuanto momento práxico (apropiación y creación de posibilidades intelectivas), la intelección tiene un origen y una finalidad práxicos y, en cuanto tal, está condicionada por intereses más o menos explícitos. Así como toda praxis está condicionada por y responde a ciertos intereses, así también su momento intelectivo.

No existe praxis desinteresada. Tampoco la praxis del reinado de Dios. Toda acción, toda praxis está estructurada y dinamizada a partir y en función de determinados intereses que pueden estar o no explicitados y que pueden ser más o menos legítimos desde el punto de vista evangélico. Incluso la acción más gratuita, es una acción interesada. Cuando se reacciona a ciertos acontecimientos o situaciones de un modo o de otro, optando por determinadas posibilidades de re-acción/inter-acción dentro del conjunto de posibilidades disponibles, se actúa siempre por alguna razón o por algún interés que puede estar en conflicto con otros intereses. $Y$ esto condiciona y determina en buena medida la actividad intelectiva en cuanto momento de la praxis. No podría ser de otra manera. Si la intelección es un momento de la praxis y si la praxis está estructurada a partir y en función de determinados intereses, es claro que esos intereses estruc-

hace algo nuevo, no solo se actualiza una posibilidad, sino que se constituye el principio histórico de lo humanamente posible» (Ibíd., 560). 
turan y determinan, de alguna manera y en alguna medida, el momento más propiamente intelectivo de la praxis.

Primero, por su origen y finalidad práxicas. «El conocer humano [...] sobre todo en disciplinas como la teología, que hace explícita referencia a realidades humanas, desempeña junto a su función de contemplación y de interpretación, una función práxica, que viene de y va a la configuración de una determinada estructura social» ${ }^{65}$. No solo procede de una praxis interesada, sino que acaba favoreciendo los intereses inherentes a esa misma praxis, en la medida en que «se convierte en favorecedora o contradictora de determinadas fuerzas sociales $»^{66}$. Y así se da con la teología: no solo procede de la praxis del reinado de Dios (origen), sino que está al servicio de esa misma praxis (objetivo). De una forma o de otra, está condicionada y dinamizada por un interés muy concreto: la realización del reinado de Dios.

Segundo, por su carácter práxico. Ya vimos que el proceso de intelección se da mediante la apropiación y la creación de posibilidades intelectivas. Y ese proceso está condicionado "por una multitud de elementos, que no son puramente teóricos $»^{67}$, sino que dependen de condiciones e intereses biográficos e históricos. La opción por investigar una realidad concreta o algún aspecto o dimensión de esa realidad y la opción por ciertas mediaciones teórico-conceptuales nunca es neutra ni se da por razones meramente teóricas. Eso que vale para el pensamiento en general, vale, particularmente, para el pensamiento teológico, mucho más propenso a «desfiguraciones y manipulaciones no siempre conscientes», dado el carácter aparentemente inverificable de muchas afirmaciones ${ }^{68}$. De ahí la necesidad de «preguntarse temática y permanentemente a qué mundo social responden, ya que ni siquiera una formulación puramente teórica se explica, en todo su sentido, sólo desde sí misma» ${ }^{69}$. Ahora bien, «la actividad teológica, además de estar sometida a múltiples presiones de orden social, que si no se desenmascaran mistifican sus resultados, tiene que echar mano de recursos teóricos, que pueden ser resultado de ideo-

65 Íd., «Hacia una fundamentación del método teológico latinoamericano» en ob. cit., 210.

66 Ibíd., 214.

67 Ibíd., 209s.

68 Íd., «La teología como momento ideológico de la praxis eclesial», ob. cit., 165.

69 Íd., «Hacia una fundamentación del método teológico latinoamericano» en ob. cit., 210. 
logizaciones más o menos larvadas». De una o de otra forma, implícita o explícitamente está siempre condicionada por intereses más o menos legítimos desde el punto de vista evangélico.

Sea por su origen y fin práxicos (reinado de Dios), sea por su carácter práxico (apropiación de posibilidades teórico-conceptuales), el hacer teológico está siempre condicionado y dinamizado por determinados intereses que lo convierten en una actividad constitutivamente práxica, valga la redundancia.

\section{Verificación e bistorización de la teología}

Por fin, el carácter práxico de la teología tiene que ver con su verificación y con su historización. En cuanto momento intelectivo de la praxis del reinado de Dios, la teología está al servicio de esa praxis y tiene en ella su lugar y su principio de verificación.

Por un lado, la teología tiene en la praxis del reinado de Dios su lugar y su principio de verificación fundamentales. En cuando intelección de una realidad histórico-práxica (reinado de Dios), verifica su veracidad en esa praxis y lo hace práxicamente. De modo que la praxis, además de lugar de experiencia o comprobación de la teoría (dónde), se constituye en principio con el cual se mide o se pondera su veracidad (cómo). Si es teoría de una praxis, la teología puede y debe ser comprobada en esa praxis ( $l u$ gar) y puede y debe ser practicable-historizable (principio). En verdad, dice Ellacuría, «una teoría teológica que no sea verificable en la praxis teologal, carece al menos de una dimensión esencial suya que es la historicidad. Pueden darse partes o aspectos de una teoría que no sean verificables de forma directa e incluso que su verificabilidad de forma indirecta no sea constringente. Pero al ser la teoría teológica un modo de teorización de una fe que es salvífica, tiene como totalidad que encontrar alguna forma de verificación histórica de ese carácter salvífico» ${ }^{70}$.

Por otro lado, la teología está al servicio del reinado de Dios y debe encontrar alguna forma de realizarlo. No está interesada solamente en inteligirlo, sino también en hacerlo realidad. Y ese interés condiciona y determina de alguna manera el propio proceso de intelección. En cuanto momento intelectivo de una praxis concreta (reinado de Dios), la teología está condicionada y orientada por los intereses inherente a esa praxis (su realización histórica). No es una actividad neutra o desinteresada ni se de-

70 Íd., «Relación teoría y praxis en la teología de la liberación», ob. cit., 241. 
sarrolla de modo absolutamente objetivo: sus opciones teórico-conceptuales están íntimamente ligadas a sus intereses práxicos; no solo proviene de la praxis (su momento intelectivo), sino que está orientada a esa misma praxis (su meta) y por eso debe encontrar alguna forma de realización (historización). No es que primero se haga teología (teoría) y después se procure realizarla (praxis), como si el interés práxico no fuese inherente al desarrollo del momento intelectivo de la praxis. Por eso mismo, dice Ellacuría: «Una teología absolutamente irrelevante para una situación histórica determinada, además de despotenciar la praxis teologal requerida, deja de ser un intelectus fidei para ser un estudio de inoperatividades ${ }^{71}$.

Sea por su lugar y principio de verificación (praxis del reinado de Dios), sea por su finalidad (realización o historización del reinado de Dios), la teología en cuanto intelección tiene un carácter intrínsecamente práxico.

\section{Conclusión}

Toda esta discusión sobre el carácter práxico de la teología puede parecer excesivamente especulativa y abstracta e, irónicamente, con poca e ninguna relevancia e incidencia práxica. Sin embargo, es mucho más determinante y decisiva en el quehacer teológico y tiene muchas más implicaciones prácticas de lo que parece a primera vista.

Al fin y al cabo, como afirma Antonio González, a propósito de la primacía de la práctica en la TdL, «el punto de partida de la teología determina decisivamente la perspectiva utilizada para abordar teológicamente esos problemas [sociales, económicos, ecológicos etc.]. Si la teología arrancara, por ejemplo, de la pregunta por el sentido de la vida, el diálogo cultural entre las distintas cosmovisiones se situaría en el primer plan de interés, mientras que otros problemas humanos se relegarían a un segundo término o se excluirían del campo de la teología. La elección adecuada del punto de partida de la teología puede determinar decisivamente la formulación del mensaje que el cristianismo quiere transmitir a una humanidad atravesada por enormes conflictos» ${ }^{72}$.

Por tanto, asumir de modo consciente y consecuente, el carácter práxico de la teología (realidad a ser inteligida, proceso de intelección, carácter interesado del conocimiento, verificación e historización de la teología),

71 Ibíd., 241s.

72 A. GonZÁLEZ, «La vigencia del 'método teológico' de la teología de la liberación», ob. cit., 669. 
498 | Francisco de Aquino

además de hacer la actividad teológica más crítica, porque más consciente de sí misma, la hace más bíblica (conocer - experimentar - hacer) y más relevante históricamente (búsqueda de mediaciones prácticas y teóricas para la realización del reinado de Dios en nuestro mundo). Al fin y al cabo, ¿qué es conocer a Dios sino amarlo (1Jo 4,8), practicar su voluntad (1Jo 2,3ss), hacer justicia a los pobres y oprimidos (Jr 22, 16;Mt 25, 31-46)?

Traducción: P. José Andrés Fayos, S.J. 
Resumen: Este estudio aborda, desde un punto de vista estrictamente epistemológico, la problemática del carácter práxico de la teología. En este sentido, se trata de determinar los vínculos constitutivos y determinantes del proceso del conocimiento teológico (teoría) con la realidad a ser conocida por la teología (praxis). En la hipótesis de esta investigación, la praxis será vista como momento constitutivo y determinante del conocimiento teológico en cuanto tal. Luego de analizar la problemática teoría-praxis, se la sitúa en el horizonte teológico en perspectiva epistemológica. A continuación, se explicita el carácter práctico de la teología, el que está estrechamente relacionado con la realidad a ser inteligida por ella, el desarrollo de la actividad intelectiva, su carácter interesado y, finalmente, con el proceso de verificación y de historización de la teología.

Palabras clave: Teología práctica, teoría-praxis, epistemología, Teología de la Liberación.

Abstract: This study examines the praxical character of theology from a strictly epistemological point of view. In this regard, it is about determining the fundamental and decisive connections between the process of theological knowledge (theory) and the reality to be known by the theology (praxis). In the hypothesis of this study, praxis is seen as a fundamental and decisive moment of theological knowledge per se. After analyzing the theory-praxis problem, it situates it on the theological horizon from an epistemological perspective. The following article specifies the practical character of theology, which is closely related to the reality to be comprehended through it, to the development of intellective activity, to its interested character and, finally, to the verification and historization process of theology.

Keywords: Practical theology, theory-praxis, epistemology, Liberation Theology. 
